\title{
O DEDO APONTANDO A LUA: EXPERIMENTANDO O CONTATO ENTRE GESTALT-TERAPIA E ZEN BUDISMO
}

\author{
The finger pointing to the moon: experiencing the contact between Ge- \\ stalt Therapy and Zen Buddhism \\ El dedo apuntando a la luna: experimentando el contacto entre la Tera- \\ pia Gestalt y el Budismo Zen
}

\begin{abstract}
Resumo: Na virada dos séculos XIX e XX ocorre maior interesse entre intelectuais ocidentais nas religiões e filosofias do Oriente. Alguns autores deste período e alguns contemporâneos nossos pontuam que o budismo não se caracteriza como uma religião, nem uma filosofia. O próprio Zen Budismo se apresenta como uma metodologia para o treinamento da mente buscando o desenvolvimento pessoal. Em meados do último século, a Gestalt-terapia emerge em meio ao diálogo das ciências ocidentais com diversas influências orientais. Atualmente, temos poucas publicações brasileiras que abordam as interfaces entre estas duas tradições e este artigo busca discutir possíveis interfaces entre a abordagem gestáltica e o Zen. Assim, apresentamos brevemente a história, alguns pressupostos, conceitos e práticas essenciais do Zen Budismo e convidamos o leitor a uma reflexão sobre a compreensão da meditação como prática experiencial a partir de paralelos observados nestas tradições. Sabemos que meditação e psicoterapia gestáltica são caminhos distintos, porém observamos algumas aproximações que denotam a possibilidade dessas metodologias serem complementares para o desenvolvimento pessoal. Este diálogo também nos abre campo para a reflexão sobre o ensino e a prática meditativa durante a formação de Gestalt-terapeutas e seu uso clínico.
\end{abstract}

Palavras-chave: Gestalt-terapia; Zen Budismo; Meditação; Zazen; Experimento.

\begin{abstract}
At the turn of the twentieth century there is a growing interest in Eastern religions and philosophies among Western intellectuals. Some authors from this period and also contemporary ones point out that Buddhism is not characterized as a religion, nor a philosophy. Zen Buddhism presents itself as a methodology for training the mind in pursuit of personal development. In the middle of the last century, Gestalt therapy emerges amidst the dialogue of Western sciences with various oriental influences. There are currently few Brazilian publications that address the interfaces between these two traditions and this article seeks to discuss possible interfaces between the Gestalt approach and Zen. Thus, it briefly presents its history, some beliefs and concepts, and essential practices in order to invite the reader to reflect on meditation as an experiential practice and parallels observed between these traditions. Meditation and Gestalt Therapy are distinct paths, but some likelinesses denote the possibility of these methodologies being complementary to one another for personal development. This article also invites the reader to reflect on teaching and practicing meditation during clinical training and its clinical use.
\end{abstract}

Keywords: Gestalt therapy; Zen Buddhism; Meditation; Zazen; Experiment.

Resumen: Al rededor del siglo XX, hay un mayor interés entre los intelectuales occidentales sobre las religiones y filosofías orientales. Algunos autores de este período y algunos de nuestros contemporáneos señalan que el budismo no se caracteriza como una religión ni una filosofía. El propio Budismo Zen se presenta como una metodología para entrenar la mente en la búsqueda del desarrollo personal. A mediados del siglo pasado, la Terapia Gestalt surge en entre el diálogo de las ciencias occidentales con diversas influencias orientales. Actualmente hay pocas publicaciones brasileñas que aborden las interfaces entre estas dos tradiciones y este artículo busca discutir posibles interfaces entre el enfoque Gestalt y el Zen. Por lo tanto, presentamos brevemente la historia, algunas ideas, conceptos y prácticas esenciales del Zen e invitamos el lector a pensar sobre la comprensión de la meditación como práctica experiencial desde los paralelos observados entre estas tradiciones. Sabemos que la meditación y la psicoterapia gestáltica son caminos distintos, pero observamos algunas aproximaciones que denotan la posibilidad de que estas metodologías sean complementarias para el desarrollo personal. Este diálogo también convida a la reflexión sobre la enseñanza y la práctica meditativa durante la formación de terapeutas y su uso clínico.

Palabras-clave: Terapia Gestalt; Budismo Zen; Meditación; Experimento. 
Estudar o Caminho de Buda é estudar a si mesmo. Estudar a si mesmo é esquecer-se de si mesmo.

Esquecer-se de si mesmo é ser

iluminado por tudo que existe. Transcender corpo e mente seu e dos outros. Nenhum traço de iluminação permanece e a Iluminação é colocada à disposição de todos os seres (Dogen Roshi, citado por Coen

Roshi, 2018).

\section{Introdução}

O budismo surgiu na Índia há cerca de 2600 anos. Depois de fugir de seu castelo e negar o futuro que seu pai planejava para ele, Xaquiamuni Buda, então Sidarta Gautama, realizou diferentes tipos de práticas com mestres de sua época. Vagou como asceta com um grupo de seguidores por cinco ou seis anos e percebeu que submeter-se a restrições não lhe permitiria saber o significado da vida. A tradição conta que após sete dias sentado meditando debaixo de uma árvore, Xaquiamuni Buda deu-se conta de que todos os seres são iluminados e que os pensamentos são ilusórios (Fabbro, Capurso \& Crescentini, 2014; Scott \& Doubleday, 2000; Suzuki, 1956; Watts, 2016). Ao longo dos anos, o número de seguidores cresceu, assim como sua fama. $\mathrm{O}$ que se segue é o crescimento deste movimento na Índia, sua migração para a China e o sudeste asiático.

Por volta de 520, o monge Bodhidharma recebe instruções de seu mestre para ir para a China (Scott \& Doubleday, 2000; Suzuki, 1956; Watts, 2016). Ele acata as orientações e introduz uma nova forma de budismo, mais focada na meditação, no templo Shaolin. Em sânscrito, tal prática é conhecida como Dhyana, a qual recebeu na China a transliteração de Ch'an ou Ch'na-na (Suzuki, 2017; Watts, 2003, 2016). Bodhidarma também é conhecido como patrono das artes marciais por ter iniciado o treinamento físico dos monges a fim de que pudessem se defender de potenciais agressores.

A linhagem se seguiu a partir deste patriarca com vários mestres. Pouco mais de setecentos anos depois, o monge MyØan Eisai introduz o Zen no Japão. A escola Rinzai se tornou muito popular entre os samurais devido à praticidade do treinamento e seguiu por muitos anos associada à aristocracia guerreira japonesa durante o período feudal de xogunato. Algumas décadas após Eisai trazer uma renovação do budismo no Japão, outro monge retorna da China com ensinamentos Zen. Eihei Dogen recebeu treinamento Rinzai, mas, ainda descontente com a falta de resposta para suas indagações, partiu para a China em busca de ensinamentos que o pudessem auxiliar no seu desenvolvimento espiritual. Dogen retornou ao Japão anos mais tarde e, após algum tempo, fundou seu próprio templo. Uma das principais diferenças a se destacar, principalmente pelo fundo cultural no período de sua fundação, é que a escola Soto considera a igualdade de homens e mulheres no caminho da iluminação e preza pela expressão dessa nas atividades cotidianas. Essas são as duas escolas budistas de maior abrangência no Japão e ganharam maior influência no Ocidente com o aumento do interesse nas culturas orientais na virada do século XIX para o XX.

O processo de introdução de filosofias e culturas orientais no Ocidente no século passado conviveu com adaptações modernas e a laicização das práticas meditativas (Prudente, 2014). Escolas de pensamento oriental, notadamente o budismo, atravessam a psicologia ocidental. Alguns autores contemporâneos entendem o budismo como um sistema psicológico e não de cunho filosófico ou religioso, como é comumente percebido pelo senso comum (Barendregt, 1987; Barrett, 1956; Fulton \& Siegel, 2016; Mikulas, 2007; Rusilo, 2017). Durante tal período, muitos pensadores demonstravam interesse por filosofias orientais e em meados do século XX o budismo já despertava a atenção de artistas, jovens da contracultura e cientistas (Prudente, 2014).

Barendregt (1987) e Fulton \& Siegel (2016) chegam a afirmar que o budismo tem status de ciência empírica, desenvolvida por experimentação direta de diversos autores ao longo de muitas gerações e se propõe oferecer soluções práticas para a cessação do sofrimento. Se reconhecermos a apropriação dos ensinamentos de Xaquiamuni Buda por diversas culturas, ainda assim o Zen Budismo não pode ser considerado uma religião num sentido estrito, como comumente se compreende, já que não é teista nem ateísta (Suzuki, 2017). Nem poderia ser considerada uma filosofia (Barrett, 1956). O Zen é, na verdade, um treinamento para perceber a realidade como é (Rusilo, 2017; Suzuki, 2017), sendo, assim, prático e não apegado a explicações intelectuais e metafísicas (Joslyn, 1977; Suzuki, 1956; Suzuki, 1994; Veras, 2013). O Zen é algo a ser vivido com abertura à dúvida e à incerteza, ao nunca totalmente acabado, já que não oferece respostas intelectuais e muitas vezes a lógica é coloca à prova, acolhendo o movimento e a impermanência (Joslyn, 1977; Scott \& Doubleday, 2000; Suzuki, 1956, 2017; Suzuki, 1994). O que alcançamos na prática sentada, que apresentaremos mais adiante, deve ser levado para o dia a dia nos relacionamentos e em todas as atividades que realizamos, como na alimentação, no banho ou mesmo no trabalho ou nas tarefas domésticas.

A Gestalt-terapia, por sua vez, é fruto do movimento contracultural em meados do século passado e foi desenvolvida por Frederick Perls, Laura Perls e Paul Goodman junto ao "Grupo dos Sete”. Nossa abordagem sintetiza vários referenciais 
culturais e intelectuais presentes nas décadas de 1940 e 1950 em uma nova Gestalt, apresentando uma alternativa aos modelos psicanalíticos e comportamentais de então (Frazão, 2013; Yontef \& Jacobs, 2010). A sistematização proposta por esses autores recebeu forte influência de filosofias orientais, tais como o Taoísmo e o Zen Budismo (Helou, 2015; Naranjo, 2013; Veras, 2013; Yontef \& Jacobs, 2010), porém essas influências nem sempre são exploradas a fundo no debate teórico ou utilizadas como instrumentalizadoras de intervenções na prática clínica como temos visto nas escolas cognitivistas nas últimas décadas.

Temos poucas publicações no Brasil que abordam a meditação, a psicologia budista e as influências orientais na clínica psicoterápica através de uma visada fenomenológica ou gestáltica. Podemos destacar na literatura as dissertações de Rosmaninho (2010), a respeito da influência da meditação vipassana em sua formação clínica como terapeuta com enfoque fenomenológico, e de Veras (2005), discutindo aproximações de conceitos da Gestalt-terapia e do Zen Budismo. Também devemos reconhecer o capítulo de Veras (2013) abordando a influência do pensamento oriental em nossa abordagem. Rosmaninho (2010) ressalta como a meditação lhe ofereceu um caminho para se reapropiar de si mesma, compreender a equanimidade e a impermanência, e aprender sobre compaixão e autenticidade.

Veras $(2005,2013)$ afirma que a interlocução entre Gestalt-terapia e Zen Budismo é possível, desde que reconheçamos que as especificidades de cada tradição e suas aproximações e distanciamentos. Assim, convido o leitor a essa reflexão primeiramente a partir de nossos pressupostos teóricos, em seguida tomando os experimentos como possibilidade de mudanças de ordem ontológica e delineio algumas considerações levantadas pela minha vivência com o Zen Budismo ao final do texto.

\section{Gestalt-terapia e psicologia budista: um (re)encontro possível?}

A proposta de Fritz Perls e seus colaboradores contestava a clínica psicanalítica de meados do século XX e necessitava de uma nova base filosófica para sustentar sua teoria e prática. O encontro com Paul Goodman e sua contratação como ghost writer marcou a emergente abordagem gestáltica de forma ímpar. Trazer uma leitura fenomenológica e repensar a noção psicanalítica de ego privilegiando o processual possibilitou produzir um novo elemento descritivo. O self seria o processo presente na fronteira entre organismo e ambiente, assimilador de novidades e promotor de crescimento integrado e coeso (Helou, 2015). Goodman descreve o "bom contato" deixando clara a influência de Otto Rank, Martin Buber, e Aristóteles, do Taoísmo e da fenomenologia existencialista. Crocker (2014) afirma que o paradigma aristotélico é fundamental à Gestalt-terapia, uma vez que prioriza a mudança, a contextualização, a compreensão através da experiência empírica. Na proposta de Goodman, o objeto ocuparia todo o campo percebido, nada mais seria experienciado. O 'Tu' e o 'Eu' anteriormente percebidos em dualidade mergiriam em uma figura única e, findado o contato, nenhum dos dois seriam mais compreendidos a partir da concepção prévia (Mann, 2010; Stoehr, 1994).

O novo modelo apresentado já em 1951 indicava a horizontalidade do 'Eu' e do 'Tu' e a potência criadora do contato. Contudo, Fritz Perls parecia não ter rompido completamente com a psicanálise como bem aponta Helou (2015). Ao final da vida, Fritz faz certa revisão de seu legado e retoma descrições que se aproximam mais de uma descrição estruturalista, distanciando-se das contribuições advindas de sua parceria com Goodman. Fritz Perls e Paul Goodman também se apropriaram dos ensinamentos budistas e lhes deram uma nova feição dentro do arcabouço da escola que fundaram no início da década de 1950 com Laura Perls e demais membros do "Grupo dos Sete”. Talvez, Claudio Naranjo, discípulo de Fritz Perls e Jim Simkin em Esalen, seja um dos gestaltistas que mais enfaticamente defendeu o uso da meditação na psicoterapia (Fabbro, Capurso \& Crescentini, 2014; Naranjo, 2005, 2013).

O debate sobre o conhecimento do mundo e nossa relação com ele parte do caráter intencional da consciência e é assunto compartilhado pelas bases filosóficas da Gestalt-terapia e do Zen. Husserl afirma não existir dicotomia sujeito-objeto já que a consciência é sempre 'consciência-de' (Holanda, 2010; Mann, 2010; Nizamis, 2012). Dessa maneira, considerar sujeito e objeto separadamente incorreria em erro metodológico para a devida descrição dos fenômenos. Esta noção dialógica-fenomenológica é a referência que Goodman buscou para sustentar a clínica proposta por Perls, um paradigma no qual um 'Eu' somente é possível na sua relação com um 'Tu', significando-a ao vivê-la (Stoehr, 1994). A Gestalt-terapia poderia ser considerada, então, uma psicologia compreensiva, tendo esta relação com a metodologia proposta por Husserl, orientada para a descoberta, integrativa e calcada na intencionalidade (Holanda, 2009).

A abordagem fenomenológica influencia a Gestalt-terapia notadamente na tentativa de aproximação com o cliente, permanecer aqui e agora, e explorar a consciência e sua produção de sentido na relação entre a pessoa e o mundo. Temos uma tendência cognitiva a estereotipar nossa percepção das coisas, de tomar tudo como um "isso aí mesmo" ao qual não precisaria dedicar maior atenção. A Fenomenologia vem nos lembrar que tal atitude natural é um erro, tanto na produção científica, como era a intenção de Edmund Husserl, quanto na forma que encaramos as dimensões física, psicológica 
e ontológica, como vemos nos desdobramentos existencialistas de Maurice Merleau-Ponty e Martin Heidegger.

Nizamis (2012) fala de a intencionalidade permear pensamentos, julgamentos e emoções, sendo fundamental em todos os níveis e modos da consciência, inclusive quando pré-linguística (como podemos observar na atividade de neurônios-espelho). Para o autor, subjetividade, intencionalidade e consciência são inseparáveis e essenciais para sermos 'conscientes-de' e experienciarmos nossa relação conosco mesmos, o mundo e os outros que aqui habitam. Segundo a tradição budista, a consciência é um fenômeno que aparece para qualquer dos seis sentidos (visão, audição, olfato, gustação, tato e pensamento) e a prática meditativa auxilia a revelar a característica pré-reflexiva da 'consciência-de' (Nizamis, 2012; Suzuki, 2017). Curiosamente, Polster \& Polster (2001), na tradição gestáltica, descrevem sete funções de contato (olhar, escutar, cheirar, degustar, tocar, pensar e movimentar-se). Assim, convido aos colegas para explorar tal ponto de contato entre as duas.

O diálogo entre as tradições orientais milenares e a emergente psicologia científica há pouco mais de um século retoma não somente o debate sobre a compreensão de self como também acerca das técnicas que permitiriam ter melhor acesso a ele. $\mathrm{O}$ método de investigação introspectivo proposto por William James, por exemplo, focaliza a atenção aos próprios processos mentais e corporais, se aproximando muito das técnicas psicofísicas yoguicas (Ferreira, 2006). Aqui faz-se necessário lembrar que o Yoga prescreve a prática de Dhyana, isto é, meditação, como forma de cultiva da qualidade de vida e desenvolvimento espiritual. James foi um dos primeiros autores a vislumbrar ainda na virada dos séculos XIX e XX a possível influência do budismo na psicologia científica ocidental (Epstein, 2013). Budismo de Gestalt-terapia têm o foco na flutuação dos processos organísmicos, sejam eles substanciados (físicos) ou experienciais (subjetivos). $\mathrm{Na}$ verdade, nos lembra Ferreira (2006), esta separação em dimensões objetiva e subjetiva é feita por nós ocidentais e não é encontrada nos escritos védicos ou budistas. Uma das inovações da Gestalt-terapia frente à Psicologia em meados do século passado é navegar no viés vitalista do movimento humanista e firmar um discurso holista, em contraposição ao discurso mentalista e dualista de então, que separava as dimensões objetiva e subjetiva. Mais adiante, vemos uma migração da referência holística de Jan Smuts para uma perspectiva de campo sob influência de Kurt Lewin. Gestalt-terapeutas são compreensivos, porém diretos e práticos, o que nos aproxima de uma ideia de existencialismo operacional, como destaca Resnick (1977). Para nós, qualquer teorização ou explicação sistemática, assim como no Zen, seria um erro (Joslyn, 1977; Naranjo, 2013; Perls, 1977; Suzuki, 1956; Suzuki, 1994).

Joyce e Sills (2016) pontuam que claramente existem sobreposições e diferenças nos conceitos gestálticos e da psicologia budista que têm influenciado as terapias cognitivas contemporâneas. Identificamos diferenças, por exemplo, entre a compreensão sobre estar aware - estar em contato e saber do contato - e estar mindful - permanecer no momentopresente eaceitar o que ocorre sem interferir, acompanhando a experiência. Enquanto na Gestaltterapia temos por objetivo aumentar a awareness de qualquer figura específica, ou seja, focamos na figura a fim de fomentar sua nitidez e energia, nas abordagens de atenção plena (mindfulness) a visão é ampliada ou uma metavisão para o monitoramento da emergência de uma figura após a outra, sem qualquer preferência. Um segundo aspecto relevante levantado pelos autores é que a Gestalt-terapia tradicionalmente afirma a apropriação das reações (ênfase no 'Eu' responsável pelo contato), quando, por outro lado, a atenção plena, como na perspectiva de não-eu do budismo, somos convidados a uma desidentificação com essas reações, considerandoas como ocorrências não-autorais e sim coautorais, uma vez que somos atravessados por diversos condicionantes, isto é, se assim podemos "traduzir" para gestaltês, compreendendo os fenômenos como emergências do/no campo. Talvez, aqui podemos reconhecer divergências entre uma concepção organísmica e holística que preza pelo autossuporte, muito em voga nas décadas de 1950 e 1960, e outra orientada ao campo, como se desenvolveu ao final do século passado. Para o Zen, todos os fenômenos são interdependentes (Nizamis, 2012; Suzuki, 2017; Suzuki, 1994; Veras, 2013; Watts, 2016) e, de igual maneira, uma clínica baseada nesta psicologia convida à redução da reatividade da pessoa aos condicionantes incidentes e à desidentificação com a autoria dos fenômenos (Epstein, 2008, 2013, 2019). A escola Sotoshu, iniciada pelo mestre Dogen, considera que tudo possui natureza búdica, inclusive nossa mente (Sugawara, sem data; Suzuki, 1994; Watts, 2003, 2016).

O Zen tem como objetivo a experiência direta da realidade, sem a necessidade de descrição por palavras ou teorizações, ou seja, que o praticante possa experienciar de maneira direta, imediata (Suzuki, 1994; Suzuki, 2017; Watts, 2016). O Zen extrapola o psicológico, o usa como um caminho para enfatizar o ontológico (Barrett, 1956; Veras, 2005, 2013). Dessa mesma maneira, a Gestaltterapia busca a transmissão de uma atitude, de uma relação, de uma disposição. Não buscamos saber algo racionalmente, mas estar aware e assimilar o nutritivo em cada contato. A Gestalt-Terapia e o Zen têm por objetivo alcançar um nível de apreensão pré-reflexivo, ou seja, radicalmente empírico e fenomenal (Joslyn, 1977). A aprendizagem da nova 
postura e a compreensão da realidade exige superar uma relação puramente racional com o fenômeno, uma vez que é a experienciação que revela a realidade.

Apesar do enfoque fenomenológicoexistencial ser um viés compreensivo comum a ambas, principalmente por incentivar uma atitude fenomenológica, de apreensão pré-reflexiva, ou uma mente de principiante, podemos também notar movimentos distintos nas duas tradições. A Gestalt-terapia parece se aproximar mais da ideia de ativamente mudar a situação, mesmo que seja ao se aceitar quem se é e fomentar a autoexpressão (Beisser, 1980; Naranjo, 2013; Resnick, 1977). Contudo, não há como prever qualquer direção da mudança (Van Dusen, 1977). Reconhecer o que se apresenta, como estamos naquele momento, e como nos relacionamos com isso é despertar para o emergente e nos deixar conduzir pela situação (Naranjo, 2013; Perls, 1977). Essa é uma atitude análoga à postulada na psicologia budista ou mesmo na psicanálise (Epstein, 2008, 2013; Naranjo, 2013). A primeira nos convida a reduzir a intelectualização, aceitar o que se apresenta, confirmando a experiência sem julgamento. A outra tem como pressuposto paralelo à associação livre a manutenção da atenção flutuante (Epstein, 2008; Naranjo, 2013). Ambas as atitudes são muito próximas da indiferença criativa sugerido por Solomon Friedlander e que serviu de inspiração a Fritz Perls (Perls, 1979; Tsallis, 2014).

A prática meditativa nos permite experimentar sensações, emoções, comportamentos e pensamentos sem julgar, mesmo que sejam polaridades conflitantes. Isto nos possibilita aceitar o que se apresenta, o emergente, inclusive a complementariedade dos opostos (Dovalí, 2017; Veras, 2013). O budismo acredita que esta mudança pode acontecer, que devemos reconhecer quem somos a cada momento, mas não aposta nisso como um objetivo ou uma garantia. Sobretudo no Zen, privilegia-se o esvaziamento do 'Eu', o desapego às emergências como fruto único e direto das ações do 'Eu', em direta contraposição com a centralidade organísmica da Gestalt-terapia de Fritz Perls e a dualidade característica de Martin Buber. Aqui encontramos novamente paralelos com uma terceira via que transcende o dualismo das polaridades, como na proposta do Caminho do Meio da escola budista Madhyamika iniciada por Nagarjuna, superando tanto o discurso absolutista como o niilista (Epstein, 2008; Suzuki, 1956). A fertilidade transformadora reside, assim, no vazio fértil, na suspensão do julgamento, na manutenção do contato com a experiência e no esvaziamento do 'Eu' (Epstein, 2008, 2013; Van Dusen, 1977).

A psicologia budista aparenta maior proximidade com os teóricos do self que herdam de Paul Goodman uma compreensão processual e, porque não dizer, de impermanência. Uma das propostas do Zen Budismo para atacar a dualidade, inclusive na separação entre a pessoa e o restante do universo, é indagar “quem sou eu?” (Suzuki, 1956, 2017). Tal questionamento nos remete ao processo de investigação e desconstrução inerente à psicoterapia, sobretudo para aqueles que se referenciam num self plenamente processual. Para o budismo, o sofrimento advém justamente da ilusão do 'Eu' como estrutura permanente (Epstein, 2013; Veras, 2005; Watts, 2003). Este 'Eu' aparente é uma ilusão na concepção budista, pois pressupõe uma separação do restante, como se a figura fosse independente do fundo. Logo, pratica-se zazen (meditação sentada) ou enfrentase um koan (enfrentamento de impasses lógicos) a fim de retomar a percepção da unicidade de todas as coisas (Suzuki, 1994; Watts, 2003, 2016).

A abertura e o acolhimento da impermanência do Zen encontram um paralelo na indiferença criativa e na teoria paradoxal da mudança da Gestalt-terapia (Beisser, 1980). Nesta correlação, entendemos que o sofrimento surge da não abertura, da fixação e do apego, e cessa quando reconhecemos quem somos a cada momento e compreendemos a impessoalidade dos fenômenos (Watts, 2003; Epstein, 2013). Aquele que vive em meditação, ou experienciando plenamente o aqui-agora, está presente de forma fluida e saudável. Estamos sempre em contato e experienciando, nos diz Ribeiro (2006), seja fazendo algo ou não, seja falando ou em silêncio, em movimento ou parados.

Diversos autores consideram o budismo como um caminho que favorece a diminuição e cessação do sofrimento humano (Barendregt, 1987; Suzuki, 2017; Watts, 2016). Esta é a proposta do treinamento e da tradição iniciada com Xaquiamuni Buda na Índia há milênios. Este objetivo é possível através da fenomenologia experimental, isto é, da investigação da consciência como ela se apresenta para a pessoa na sua auto-observação com práticas meditativas (Barendregt, 1987; Epstein, 2008), senão de um "intuicionismo radical”, como o Zen Budismo (Barrett, 1956). A superação do sofrimento pode ser alcançada por duas vias (Barendregt, 1987; Watts, 2016): mudando a situação na qual estamos ou a maneira como a percebemos. Barendregt (1987) nos alerta que uma ou outra alternativa será mais bemsucedida de acordo com as circunstâncias. As dores do nascimento, envelhecimento, adoecimento e morte, por exemplo, são inerentes ao viver. Contudo, o sofrimento advém de nossa relação com aquilo que se apresenta. O sentido que damos às vivencias é que dá o tom do sofrimento que experimentamos. A tradição budista afirma que nirvana (estado no qual estamos incondicionados ou superamos os apegos sensoriais, materiais e existenciais) se equivale ao samsara (estado oposto ao anterior, no qual ficamos presos aos condicionantes), na medida que o que diferencia ambos é a relação estabelecida (Suzuki, 2017; Watts, 2016). Em gestaltês, isso significa que se mudarmos 
o contato podemos transformar a experienciação e a assimilação. Isso seria viável já que existe uma horizontalidade entre os envolvidos, a possibilidade de modificar a 'consciência-de' e o desenvolvimento de ferramentas através de práticas meditativas.

\section{Práticas meditativas e experienciação: o dedo que aponta a lua?}

A Gestalt-terapia tem a infeliz caricatura de ter uma metodologia desafiadora, frustradora e catártica em detrimento da necessidade de apoio que o cliente possa necessitar (Dolliver, 1991; Resnick, 2016). Talvez isso se deva aos vídeos de grupos conduzidos por Fritz Perls e do atendimento de Gloria produzido por Shostrom (1965) na década de 1960. Os experimentos, nossos instrumentos metodológicos básicos (Zinker, 1977), sofreram com o esvaziamento da fundamentação teórica por profissionais mal intencionados, despreparados ou pessoas que participavam de workshops de final de semana e se consideravam Gestalt-terapeutas capacitados (Resnick, 2016), e até mesmo por publicações como Gestalt-terapia explicada, do próprio Fritz Perls (1977), e Tornar-se presente, de John Stevens (1988). Compreender a sutileza do manejo clínico requer do terapeuta refinamento teórico, compromisso dialógico e experimentação pessoal na própria psicoterapia e no processo de supervisão clínica. Infelizmente, alguns profissionais insistem em não investir nesses aspectos.

As técnicas em Gestalt-terapia abrangem uma amplitude de possibilidades. Naranjo (2013) destaca que abordamos aspectos verbais e nãoverbais, introspectivas e interpessoais, bem como intervenções mais estruturadas e não estruturadas. Naranjo lembra que o Gestalt-terapeuta usa de técnicas desenvolvidas por colegas de abordagem, mas também importa e adapta de outras escolas psicoterápicas e mesmo de tradições espirituais. $\mathrm{O}$ que caracterizaria a intervenção como gestáltica, enfatiza o autor, é o enfoque dado nos pilares atualidade, awareness e responsabilidade. Logo, o experimento deve possibilitar a retomada do contato, seu enriquecimento e inovação. Não buscamos a estimulação para crescer de fora para dentro, mas a sensibilidade para reconhecer a relação consigo e com o mundo e crescer de dentro para fora (Naranjo, 2013; Ribeiro, 2006).

Essa mudança de atitude a partir de novos dados fenomenológicos acessados nos experimentos oferece condições para o contato com a realidade imediata, pessoalmente experienciada (Naranjo, 2013), de forma a ampliar a compreensão de si e o repertório comportamental (Zinker, 1977), levando à retomada da capacidade de fazer escolhas (Resnick, 2016). O experimento requer da pessoa um investimento na sua própria exploração a fim de gerar crescimento. Uma vez que estamos em contato o tempo todo, buscamos com o experimento enriquecer a relação estabelecida pela mudança de atitude frente ao emergente no campo, voltando para o vivenciado a cada momento e integrando perceber, sentir, fazer e pensar (Naranjo, 2013; Ribeiro, 2006).

Experimentar, como a meditação, não é uma prática formal e artificialmente separada, mas uma postura. Mann (2010) e Joyce e Sills (2016) compreendem a instrumentalização clínica da perspectiva fenomenológica na Gestalt-terapia a partir de três elementos básicos: 1) a redução fenomenológica, ou a tentativa de suspensão temporária de apriorismos a fim de nos aproximarmos de uma observação jamais vu ao invés de uma dejà $v u$; 2) a descrição do que é imediatamente óbvio, vivenciado e presente; e, 3) o horizontalismo dos elementos envolvidos, sendo, então, considerados igualmente relevantes, ou seja, qualquer emergência é potencialmente importante e deve ser levada em conta, seja vinda do terapeuta ou do cliente, seja o que é falado (conteúdo verbal) ou como é falado (processos e elementos não-verbais). Joyce e Sills (2016) acrescentam um quarto elemento à prática clínica fenomenológica gestáltica: a curiosidade ativa de terapeuta e cliente, que buscam juntos novidades na relação estabelecida, mantendo uma postura naïve, monitorando o que se sucede. Assim, os experimentos potencializadores da awareness, inovação técnica da Gestalt-terapia, tendem a valorizar uma apreensão pré-reflexiva do que se dá a nível dialógico, ampliando significações e a capacidade de escolher para além da estereotipia anacrônica.

Naranjo (2013) classifica as técnicas utilizadas em experimentos como supressivas, expressivas e integrativas. As primeiras buscam suprimir as evitações de contato, como nas explicações evasivas do sobreismo, na referenciação externa e no heterossuporte disfuncional do deverianismo, e na não responsabilização dos jogos manipulativos. Essas buscam criar um contexto no qual o cliente não pode mais lançar mão de estratégias de descontinuação do contato e o convoca a mudar de atitude. As técnicas expressivas fomentam o reconhecimento e a utilização de ações ativas ao invés de reativas, automáticas e condicionadas. As integrativas visam assimilar aquilo que estava dissociado ou alienado, promovendo um crescimento pelo enriquecimento da awareness e apropriação de dados no contato estabelecido.

O Zen Budismo, por sua vez, dispõe de koans, mondos, zazen e kinhin como ferramentas que auxiliam no treinamento mental e na (re)descoberta da realidade (Veras, 2005, 2013; Suzuki, 2017; Watts, 2016). Koans são perguntas paradoxais oferecidas aos alunos por seu mestre a fim de transcender a lógica ordinária e incentivar a apreensão intuitiva e direta da realidade. Uma vez oferecido pelo mestre, o discípulo deve retornar com uma resposta para a pergunta, que deve ser confirmada pelo professor 
em sucessivas entrevistas individuais. Mondos são conversas registradas entre mestres e discípulos, geralmente curtas e voltadas para a transmissão de algum ensinamento de forma simples e evidente, na própria situação de interação entre os envolvidos. A tradição budista possui muitos registros de koans e mondos que retratam a transmissão do Dharma (o conhecimento e a prática das leis e princípios que unem a teia da realidade) diretamente de mestre a discípulo.

As escolas Soto e Rinzai são as maiores e mais conhecidas, e, embora compartilhem de semelhanças quanto ao treinamento básico, cada uma privilegia algumas práticas e possui diferenças quanto a detalhes de rituais e de técnicas (Scott \& Doubleday, 2000; Naranjo, 2005). Um núcleo comum às duas escolas é a meditação sentada, o zazen (literalmente meditação sentada). A técnica é bastante prática e simples. Para sentar-se em Zen basta encontrar uma posição adequada e observar os fenômenos que se apresentam, sejam eles percepções corporais, emoções, imagens ou pensamentos (Epstein, 2019; Scott \& Doubleday, 2000; Naranjo, 2005; Suzuki, 1994; Suzuki, 2017; Watts, 2016). Tal prática pressupõe que devamos observar esses fenômenos sem apego, seja para que fiquem ou nos deixem. O praticante é instruído a deixar que eles passem diante de si como nuvens no céu, sem qualquer julgamento, com aceitação, compaixão, paciência e uma atitude de principiante. Esta atitude se caracteriza pela abertura, pela compaixão e por estar alerta (Suzuki, 1994), aguardando "pacientemente por algo-que-não-se-sabe-o-que-é” (Joslyn, 1977, p. 315). A instrução do mestre Dogen era de que o zazen fosse uma prática diária e para a qual devemos ter entrega total, ou seja, uma atitude cerimoniosa que a diferencie de outras atividades rotineiras, e consigamos libertar shin (corpo-mente) dos apegos e manifestar o verdadeiro Dharma (Sugawara, sem data; Suzuki, 1994). A instrução do shikantaza (o zazen segundo a doutrina proposta por Dogen) é para o praticante sentar-se e meditar com a única intenção de fazê-lo, não tendo qualquer outro objetivo, meta ou finalidade.

Pode-se praticar zazen sentado numa cadeira, de joelhos sentado sobre uma almofada (posição seiza), sentado com pernas cruzadas à frente do corpo (como na posição birmanesa), sentado com um pé sob a coxa contrária e o outro sobre a outra coxa (posição de meio-lótus), ou mesmo com o pé esquerdo repousando sobre a coxa direita e o pé direito sobre a coxa esquerda (posição de lótus completo). A posição corporal deve auxiliar na estabilidade do corpo para evitar o cansaço do praticante, estendendo seu tempo sentado em observação e estudo de si. Algumas técnicas podem ser usadas pelo praticante iniciante a fim de conseguir melhorar sua capacidade de concentração, como contar a respiração a cada movimento de entrada e saída do ar, ou contar a cada ciclo respiratório (Scott \& Doubleday, 2000; Suzuki, 1994). A contagem pode ser feita até dez ciclos e, caso se perca a contagem, o praticante deve voltar sua atenção gentilmente para a respiração e retomar a contagem a partir do número um. Quando a prática de zazen se estende por período mais longos, pode ser introduzido um intervalo de prática andada, também conhecida como kinhin (Scott \& Doubleday, 2000). Tal técnica permite aliviar a dormência nas pernas e evitar a sonolência do praticante. Caso o leitor tenha interesse, pode encontrar facilmente instruções de zazen e kinhin na internet ou procurar um centro de prática perto de você, seja num dojo (sala de prática), templo ou mosteiro.

A meditação é um recurso promotor de saúde desenvolvido ao longo de muitos séculos através de observação direta e rigoroso controle empírico (Olendzki, 2016; Suzuki, 1956, 2017) e registrado há pelo menos 2500 anos e consiste na promoção de sati (Germer, 2016; Naranjo, 2005). Em pali, dialeto anterior ao sânscrito no qual temos os primeiros escritos buditas, sati diz respeito a estar atento plenamente e lembrar de se voltar de forma receptiva à experiência do momento (Germer, 2016). Esta noção se aproxima bastante do que a Gestalt-terapia postula como awareness, dar-se conta de quem se é, do outro e da relação que estabelecemos (Ribeiro, 2006) ou um conhecimento pré-reflexivo do fluxo experiencial no campo (Alvim, 2014), porém não é de todo coincidente.

Pouco mais de uma década atrás, encontrávamos descrições de práticas meditativas organizadas em dois tipos básicos por autores ocidentais, que as entendiam como técnicas de autorregulação mental e fisiológica através do treino da atenção (Cahn \& Polich, 2006; Walsh \& Shapiro, 2006): samatha, que consiste nas técnicas voltadas para a concentração, focando em um fenômeno em específico presente no campo a fim de acalmar as atividades mentais (Cahn \& Polich, 2006; Epstein, 2008; Fabbro, Capurso \& Crescentini, 2014; Fulton \& Siegel, 2016; Germer, 2016; Morgan, Morgan \& Germer, 2016; Naranjo, 2005; Walsh \& Shapiro, 2006); e, vipassana, cujo objetivo é acompanhar os fenômenos emergentes através de um monitoramento aberto das emergências (Cahn \& Polich, 2006; Epstein, 2008; Fabbro, Capurso \& Crescentini, 2014; Fulton \& Siegel, 2016; Germer, 2016; Morgan, Morgan \& Germer, 2016; Naranjo, 2005; Walsh \& Shapiro, 2006) ou em seu sentido original em pali, ver as coisas como elas realmente são (Dovalí, 2017), desconstruindo a falsa percepção do 'Eu' (Epstein, 2008, 2013). Alguns autores também descrevem as práticas de amor-bondade, de compaixão e de dar e receber, tradicionalmente chamadas de metta, karuna e tonglen, respectivamente, como uma terceira categoria voltadas diretamente para as relações (Fulton \& Siegel, 2016; Germer, 2016; Morgan, Morgan \& Germer, 2016; Naranjo, 2005; 
Ribeiro, 2019; Watts, 2016).

A sistematização das práticas no contexto cultural ocidental e o aumento do interesse pela comunidade científica revelou a necessidade de classificar as técnicas de forma a orientar pesquisadores em suas investigações. Assim, Dahl, Lutz e Davidson (2015) oferecem uma nova sistematização de práticas que abarca diversas tradições confessionais e clínicas. Esses autores criaram uma tipologia de práticas meditativas e intervenções psicológicas com três famílias que se ramificam em três subgrupos de acordo com algumas especificidades. A primeira família agrega as práticas com cunho atencional, como técnicas voltadas para estabilizar a atenção de maneira focada ou através de monitoramento aberto (seja para objetos mentais, tais como figuras perceptivas, proprioceptivas, emocionais ou pensamentos, e para a própria flutuação da atenção). A prática destas técnicas auxilia na presentificação dos processos, em estar aqui e agora, sem qualquer julgamento, com reconhecimento e aceitação do que emerge. Entre as práticas Zen, esta classificação considera a contagem de ciclos respiratórios para praticantes iniciantes como uma técnica da família atencional, mais especificamente de atenção focada. A segunda família da tipologia envolve as técnicas construtivas, isto é, aquelas voltadas para alteração perceptual, de valores, de amor-bondade e de compaixão, entre outras. Tais técnicas permitiriam uma nova forma de se relacionar com o contatado, ressignificando e modificando a relação estabelecida. Na tradição Zen Budista, encontramos tal intenção ao se contemplar nossa mortalidade (Maranasati) e ao se fazer o voto de Bodhisattva, no qual o praticante se dispõe a salvar todos os seres, extinguir seus apegos, transpor os obstáculos para apreender o Dharma, e seguir o Caminho de Buddha (viver com sabedoria e compaixão) (Naranjo, 2005; Watts, 2016). A última família descrita por Dahl e colaboradores compreende as técnicas desconstrutivas ou de insight, voltadas para o questionamento de pensamentos, emoções e percepções originadas da reificação cognitiva e da noção de 'Eu'. Estas intentam colocar em dúvida a fixação em uma identidade deslocada da teia de condicionantes ou à parte do campo. Podemos considerar neste grupo as práticas zen de koan e de shikantaza (zazen).

Ferreira (2006) descreve a meditação como uma técnica para tomar um objeto específico para a atenção (num sentido de consciência intencional) a fim de criar um intervalo na dinâmica relacional, a partir do qual nos liberamos das ações impulsivas (e por que não dizer, neuróticas) e ganhamos a possibilidade de agir de maneiras mais livre e criativa. Assim, poderíamos considerar, à princípio, que práticas da primeira família acima descritas (Dahl et al., 2015) tendem ao que Figueroa (2015) chama de exercício, ou técnicas autoaplicáveis para a exploração das funções de contato e cujos resultados já são estimados. Por outro lado, técnicas das segunda e terceira famílias se assemelham mais à descrição comumente associada a experimentos, ou seja, focam na figura emergente, não possuem um fim determinado e fomentam mudanças da dinâmica do contato.

A partir da classificação proposta por Naranjo (2013), poderíamos considerar que a primeira família desta tipologia se encaixa na descrição de técnicas supressivas pela sustentação do contato estabelecido em detrimento de tentativas a partir de referenciais anacrônicos. As técnicas construtivas da segunda família, por sua vez, teriam cunho expressivo, uma vez que permitem a exploração de si e a autoexpressão. As práticas da família desconstrutiva poderiam também ser compreendidas como técnicas supressivas. Entretanto, Naranjo nos lembra de que a supressão fomenta a expressividade, e esta a assimilação. Resnick (1997) comenta que a Gestaltterapia estimula a presença e a expressividade pelo continuum de awareness tal qual as práticas atencionais e, sobretudo, desconstrutivas, haja visto que se voltam ao campo desconsiderando qualquer dualidade. $\mathrm{O}$ efeito integrativo, sugerido por Naranjo, seria resultado de manter-se em meditação informalmente em toda atividade cotidiana, como preconiza o zen. Outro ponto a considerarmos é compreender toda prática um experimento, pois a orientação última é seguir as figuras emergentes desde o momento de decidir qual técnica utilizar no momento, bem como não termos como antever com o que o praticante irá se deparar durante a meditação ou como será sua atitude após experimentá-la. O que se espera do meditador é focar em si e esquecer de si mesmo numa perspectiva reificada, reconhecendo a unicidade do todo.

A compreensão das naturezas de self e do sofrimento necessita da prática concreta da autoobservação, um estudo empírico direto, não podendo jamais se limitar à teoria gestáltica ou dos cânones ou debatedores budistas. Barendregt (1987) faz uma analogia da prática meditativa com aprender a nadar: podemos ler, assistir uma aula e conversar sobre fundamentos da natação, mas nada se compara a cair na água e nadar, pois obtemos progresso apenas se nos exercitarmos de fato. Podemos pensar a prática meditativa como formal ou informal (Demarzo \& Campayo, 2015). A formal está vinculada a técnicas específicas, geralmente feitas sentado, andando ou através de prostrações e feitura de votos no Zen Budismo. Os exercícios andando nos requisitam muita atenção ao movimento corporal e podem agregar detalhes com o tempo de prática. A prostração igualmente exige atenção do praticante e remete a aspectos compassivos inerentes a culturais orientais, não se constituindo uma prática muito frequente entre ocidentais. A meditação sentada talvez seja a mais comumente lembrada devido 
à divulgação pela mídia e sua apropriação pelos programas de terapia baseada ou informada em mindfulness (Demarzo \& Campayo, 2015; Fulton \& Siegel, 2016; Germer, 2016; Walsh \& Shapiro, 2006). Entretanto, também podemos integrar informalmente práticas atencionais, construtivas e desconstrutivas às tarefas cotidianas, de forma que possamos estar em estado meditativo nas mais variadas atividades, como comer, arrumar a casa, trabalhar ou mesmo tomar banho.

Se voltarmos nossa atenção à metodologia e ao objetivo da Gestalt-terapia para discutir a possibilidade de uso da meditação como recurso terapêutico, observamos que Resnick (2016) delineia a Gestalt-terapia como uma escola processual com base na Fenomenologia, no Dialogismo e na Teoria de Campo. Tendo essas bases de apoio, as intervenções gestálticas visam proporcionar um contraste através de um novo contato, realçando a figura que não está nítida. As diferenças entre a figura antiga e a nova geram awareness do contato estabelecido, proporcionando a possibilidade de escolha e novo direcionamento da relação. O objetivo da meditação é basicamente reconhecer os condicionantes do comportamento, memórias do passado ou expectativas do futuro que se apresentam agora, observando os estados de funcionamento que emergem (Demarzo \& Campayo, 2015; Epstein, 2019; Fulton \& Siegel, 2016; Goleman, 1999; Suzuki, 2017; Watts, 2003). Ou seja, tanto meditação quanto experimento, e por que não dizer da meditação como experimento, poderiam romper com o comportamento automatizado e anacrônico neurótico em favor do ajustamento criativo saudável pela introdução de novidade no contato. Poder reconhecer o campo é, portanto, transformador. Meditação e psicoterapia apresentam caminhos e objetivos distintos (Epstein, 2008, 2013; Veras, 2013). Talvez, a melhor alternativa, então, seria como afirma Epstein $(2008,2013,2019)$, não optar por meditação ou psicoterapia, mas usar ambas para fomentar o crescimento pessoal. Assim como a terapia, a meditação ajuda no manejo das emoções, no desenvolvimento de sentido da vida e aceitação da realidade de forma compassiva e assertiva (Demarzo \& Campayo, 2015; Epstein, 2013; Rosmaninho, 2010; Veras, 2005, 2013). Contudo, enquanto a psicoterapia tem uma proposta integrativa, a meditação busca a desconstrução e a desidentificação (Epstein, 2013).

A prática meditativa igualmente predica o enriquecimento da relação com o mundo ao compreender os condicionantes de nossos comportamentos no exercício da ação ou da não-ação, sentados em silêncio ou nas atividades cotidianas. Narranjo $(2005,2013)$ descreve o uso de meditação tanto individualmente quanto em duplas durante trabalhos em grupo e enumera cinco vantagens da tomada de consciência através da meditação que é compartilhada com outra pessoa (Naranjo, 2013):
1) estar aware e ter a capacidade de se expressar descrevendo a situação; 2) a presença de outra pessoa nos leva a aumentar nossa atenção em relação ao que se observa; 3) a meditação interpessoal (feita junto com outras pessoas) acaba por focar em conteúdos relativos à interação presentes no campo ao invés de aspectos individuais; 4) a situação interpessoal torna o centrar-se no aqui-agora mais difícil, devido às interrupções de contato, sendo uma oportunidade para evidenciar esses mecanismos; e, 5) o uso de meditação no processo psicoterapêutico permite o auxílio de um terapeuta na avaliação da autoobservação pelo cliente.

A própria relação terapêutica na Gestalt-terapia segue um viés meditativo, de atenção plena, uma vez que vislumbra o contexto relacional, o treino de estar aware, a suspensão da interpretação e da conceitualização, privilegiando a autenticidade, a expressividade e o autossuporte (Naranjo, 2013), testemunhando sem julgar o emergente e tendo autocompaixão (Resnick, 1977). No Zen, a iluminação não é uma condição perene, mas um estado no qual conseguimos reconhecer a impermanência e a natureza interdependente e una da realidade. Para a Gestalt-terapia, igualmente não conquistamos a awareness como algo permanente; ela é um estado que pode ser desenvolvido e mantido.

\section{(Re)Descobrindo o óbvio: a lua sempre esteve lá}

Por que a Gestalt-terapia contemporânea não reconhece abertamente a influência de filosofias orientais, articulando diálogos com teóricos de ambas tradições? Por que não somos ensinados e não praticamos meditação em nossa formação como Gestalt-terapeutas, já que poderíamos nos beneficiar pessoalmente e conseguir nos colocar mais atentos e dispostos na relação terapêutica? O presente texto não pretende esgotar estas reflexões, mas tão somente convidar o leitor a trazer para si tais questionamentos, estimular o estudo de influências presentes no início do desenvolvimento teórico e prático de nossa abordagem, e a prática de meditação. O intuito do presente texto é defender a associação de meditação e psicoterapia, tanto pelos terapeutas como por seus clientes, já que o crescimento buscado não é só ôntico, mas ontológico.

Terapeutas poderiam desenvolver habilidades relevantes se utilizando da meditação em seu treinamento e concomitante com sua prática profissional (Dovalí, 2017). Podemos elencar alguns aprendizados importantes, como os limites da nossa responsabilidade frente ao outro e da nossa capacidade de ajudar alguém a mudar e crescer, bem como o reconhecimento das emoções difíceis que sentimos, do que não sabemos ou podemos fazer na relação terapêutica (Epstein, 2008; Fulton, 2016; Morgan, Morgan \& Germer, 2016; Surrey \& Kramer, 2016). Percebo mudanças significativas na 
qualidade de minha presença quando estou com meus clientes, em sala de aula e nas supervisões de estágio. Tal mudança tem repercutido na relação estabelecida, na inventividade experiencial e na indiferença criativa frente à evolução das situações compartilhadas e das relatadas.

Praticar meditação e fazer psicoterapia, juntas ou separadas (melhor juntas do que separadas), fomenta a percepção do que estava desfocado ou alienado. Nosso objetivo é com ambas (re)descobrir o que sempre esteve ali diante de nós: o imediato, o óbvio. Apesar da prática meditativa formal ou informal ser autoaplicável e aparentemente repetitiva, podemos a considerar um experimento, já que cada experiência nunca é exatamente a mesma e seu intuito é de mudar a atitude frente ao emergente e saber mais do que apresenta. Assim, a meditação e os experimentos se caracterizam pela inovação, ineditismo e indiferença criativa. Por diversas vezes conflitos identificados no cotidiano se delinearam e ficaram mais nítidos durante minha prática sentada formal. A mudança de atitude frente a eles, sua aceitação e acolhimento levaram ao desapego de uma resolução específica, maior reconhecimento dos elementos do campo e a intenção dos contatos estabelecidos. O aprendido com a pergunta de fundo "quem é este que sente/ faz X?” era levado à psicoterapia para novamente ser contatado. E uma vez retirado o véu das figuras fixas, soluções se apresentavam e revelavam a ignorância do óbvio não reconhecido anteriormente.

Outro convite a ser feito é o estudo do Zen Budismo como ele se propõe, um treinamento para o desenvolvimento pessoal e a (re)descoberta da realidade. No início da jornada, diz a tradição Zen, montanhas e árvores são montanhas e árvores; em seguida, deixam de ser montanhas e árvores, para mais adiante, após a iluminação, voltarem a ser montanhas e árvores. Esta metáfora também pode ser usada para descrever o desenvolvimento através de um caminho gestáltico. A psicoterapia, se podemos considerá-la um treinamento como o Zen, nos permitiria perceber novamente o absoluto (fundo), ou seja, a unicidade de todas as coisas ou do campo, e o ir e vir das figuras (Joslyn, 1977). Mudamos a relação com o todo quando reconhecemos a nós mesmos, o que se apresenta e a nossa relação. $\mathrm{O}$ enriquecimento da awareness proporcionado pela Gestalt-terapia, assim como a iluminação do estudante do Zen, leva a novos arranjos autorregulatórios e contatuais, possibilita transformações que extrapolam o ôntico e alcançam o ontológico. O estudo comparado de ambas tradições pode auxiliar na reflexão de nosso corpo teórico, repertório técnico e atitude clínica cotidiana. Acredito que esse contato pode ser muito rico e nutritivo.

Todavia, o estudo formal não será suficiente. Como no conto tradicional budista, cabe ao estudante de si mesmo perceber que as palavras do mestre, os livros e as escrituras são apenas um veículo para auxiliá-lo a reconhecer a lua. Contudo, a lua sempre esteve lá para ser vista, não devendo aquele que procura a iluminação se apegar ao dedo que a aponta. $\mathrm{O}$ mesmo ocorre na experimentação em psicoterapia. $\mathrm{O}$ encontro dialógico com o terapeuta e os experimentos propostos são veículos para ampliar a awareness, mas não se deve ficar apegado a eles. Nem às técnicas, nem ao terapeuta, ou mesmo à teoria. Como um bote que nos ajuda a atravessar um rio, outra metáfora budista, devemos deixá-los uma vez que a travessia foi feita (Watts, 2016). O mestre lança mão de koans para que o aluno ultrapasse suas limitações e os impasses que se apresentam (Watts, 2016), descobrindo-se ser seu próprio koan (Joslyn, 1977) e permitindo-se superá-lo ao se abrir por si mesmo e compreender o sentido do que ali se apresenta (Naranjo, 2005). Nós, gestaltistas, temos uma senda muito parecida. Frustramos habilidosamente, oferecemos suporte quando preciso e auxiliamos na exploração do campo e enfrentamento de impasses.

Após anos de prática descompromissada, fiquei um tempo sem separar um espaço em minha agenda de atividades para meditar. Na verdade, somente meditei com maior frequência durante o período no qual trabalhei em um hospital psiquiátrico, onde eu e um colega fisioterapeuta ensinávamos aos pacientes internados e frequentadores de hospitaldia um pouco das técnicas que conhecíamos - ele muito mais do que eu - de Shahaja Yoga, uma tradição indiana de Dhyana. A retomada da meditação nos últimos três anos veio junto com a decisão de investir no meu desenvolvimento pessoal e das pessoas com quem tenho lido cotidianamente, e na minha formação em Gestalt-terapia, que até então se resumia ao autodidatismo, participação em congressos e workshops, e experimentação na prática clínica. Atuei por anos tendo outras referências teóricas e técnicas, mas encontrei na Gestalt-terapia um bote para atravessar o rio.

Retomar a prática meditativa fomentou meu desejo de crescimento além da teoria, o qual não deveria se restringir a minha pessoa. $\mathrm{O}$ retorno que tenho, sobretudo nos últimos meses, é bastante positivo. Além de estudar, praticar e divulgar a meditação, retomei a psicoterapia pessoal e investi ainda mais na formação profissional. A meditação me mostrou a necessidade de resolver questões e desenvolver ferramentas das quais não estava aware anteriormente. Sigo praticando shikantaza e as implicações cotidianas mais notórias são a diminuição da sensação de cansaço, o desapego das emoções e pensamentos, a melhoria da qualidade dos relacionamentos, maior alinhamento com meu propósito de vida, dentre várias outras. Retornando à frase do mestre Dogen que abre este artigo, estudar a mim mesmo me levou a experimentar o esquecimento de mim mesmo e de me unir a todas as coisas. Cuidar de si é cuidar do outro. Descobri 
que posso estar atento às figuras emergentes e contribuir para o desenvolvimento de todos a partir do autocuidado. Além disso, lembro que a separação entre o 'Eu' e o 'Outro' é ilusória numa perspectiva búdica ou de campo. Este exercício diário e contínuo é difícil e revela repercussões mais amplas do que imaginava num primeiro momento; afinal, extrapolam o aspecto organísmico e alcançam as dimensões societal e ecológica.

Zen Budismo e Gestalt-terapia buscam a transmissão direta de uma atitude, não podem ser compreendidos pelo estudo teórico ou por explicações. Este artigo é apenas uma tentativa de descrever minha compreensão e vivência, bem como convidar o leitor a este experimento. Os conceitos antes teóricos, frios e distantes se materializaram neste contato. Contudo, nenhuma explicação, reflexão ou tentativa de explicação minha seria suficiente para que o leitor compreenda o Zen ou a Gestalt-terapia. A vida deve ser vivida. O Zen e a Gestalt-terapia devem ser vividos.

Sigo estudando e praticando o Zen e a Gestaltterapia. Para mim, já não importa mais quem aponta. O dedo e a lua são um.

\section{Referências}

Alvim, M.B. (2014). Awareness: experiência e saber da experiência. Em L.M. Frazão \& K.O. Fukumitsu (Orgs.). Gestalt-terapia: conceitos fundamentais (pp. 13-30). São Paulo: Summus.

Barendregt, H. (1987, jan. 7-10). Buddhist phenomenology. Em M. dalla Chiara (Ed.). Vol. 2: Filosofia della scienza e fondamenti della probabilità e della statistica, Congresso Temi e prospetitive della logica e della filosofia della scienza conteporanee, Cesena (pp. 37-55). Bologna: CLUEB. Disponível em: <https://repository.ubn.ru.nl/ bitstream/handle/2066/17299/13374.pdf?sequence $=1>$. Acesso em: 06 ago. 2018 .

Barrett, W. (1956). Zen for the West. Em D.T. Suzuki. Zen Buddhism: selected writings of D.T. Suzuki (pp. VII-XX). Garden City, NY: Doubleday Anchor Books.

Beisser, A. R. (1980) A teoria paradoxal da mudança. Em J. Fagan \& I.L. Shepherd (Eds.). Gestalt-terapia: teorias, técnicas e aplicações (pp. 110-114). Rio de Janeiro: Zahar.

Cahn, B. R. \& Polich, J. (2006). Meditation states and traits: EEG, ERP, and neuroimaging studies. Psychological Bulletin, 132(2), 180-211.

Crocker, S.F. (2014). Uma teoria unificada. Em P. Brownell (Ed.) Manual de teoria, pesquisa e prática em Gestalt-terapia (pp. 155-186). Petrópolis: Vozes.
Dahl, C. J., Lutz, A., \& Davidson, R. J. (2015). Reconstructing and deconstructing the self: cognitive mechanisms in meditation practice. Trends in cognitive sciences, 19(9), 515-523.

Demarzo, M., \& Campayo, J.G. (2015). Manual prático de mindfulness: curiosidade e aceitação. São Paulo Palas Athena.

Dolliver, R. H. (1991). Perls With Gloria Re $\square$ reviewed: Gestalt Techniques and Perl's Practices. Journal of counseling $\&$ development, 69(4), 299-304.

Dovalí, M. (2017). Terapia Gestalt basada en atención plena. (n.p.): Author.

Epstein, M. (2019). Advice not given: a guide to getting over yourself. New York: Penguin Books.

Epstein, M. (2008) Psychotherapy without the self. New Haven: Yale University Press.

Epstein, M. (2013). Thoughts without a thinker: psychotherapy from a buddhist perspective. New York: Basic Books.

Fabbro, F., Capurso, V., \& Crescentini, C. (2014). Claudio Naranjo's contribution to meditation in the light of neuropsychology. World Futures, 70(7), 386-400.

Ferreira, M. T. (2006). A experiência do self em William James e no Budismo. Cognitio-Estudos: revista eletrônica de filosofia, 3(1), 29-41.

Figueroa, M. (2015). As técnicas em Gestalt-terapia. Em L.M. Frazão \& K.O. Fukumitsu (Orgs.). A clínica, a relação terapêutica e o manejo em Gestalt-terapia (pp. 103-128). São Paulo: Summus.

Frazão, L.M. (2013). Um pouco de história... um pouco dos bastidores. Em L.M. Frazão \& K.O. Fukumitsu (Orgs.). Gestalt-terapia: fundamentos epistemológicos e influências filosóficas (pp. 11-23). São Paulo: Summus.

Fulton, P.R. (2016). Mindfulness como treinamento clínico. Em C.K. Germer, R.D. Siegel \& P.R. Fulton (Orgs.). Mindfulness e psicoterapia (pp. 6077). Porto Alegre: Artmed.

Fulton, P.R \& Siegel, R.D. (2016). Psicologia budista e psicologia ocidental: buscando pontos em comum. Em C.K. Germer, R.D. Siegel \& P.R. Fulton (Orgs.). Mindfulness e psicoterapia (pp. 37-58). Porto Alegre: Artmed.

Germer, C.K. (2016). Mindfulness: o que é? Qual é a sua importância? Em C.K. Germer, R.D. Siegel \& P.R. Fulton (Orgs.). Mindfulness e psicoterapia (pp. 2-36). Porto Alegre: Artmed. 
Goleman, D. (1999). Trabalhando com a inteligência emocional. Rio de Janeiro: Objetiva.

Helou, F. (2015). Frederick Perls, vida e obra: em busca da Gestalt-terapia. São Paulo: Summus.

Holanda, A. (2009). Fenomenologia e Psicologia: diálogos e interlocuções. Revista da Abordagem Gestáltica: Phenomenological Studies, 15(2), p. 87-92.

Joslyn, M. (1977). Figura/fundo: Gestalt/Zen. Em J.O. Stevens (Org.). Isto é Gestalt (pp. 303-326). São Paulo: Summus.

Joyce, P. \& Sills, C. (2016). Técnicas em Gestalt: aconselhamento e psicoterapia. Petrópolis: Vozes.

Mann, D. (2010). Gestalt Therapy: 100 key points $\mathcal{E}$ techniques. New York: Routledge.

Mikulas, W. L. (2007). Buddhism \& western psychology: Fundamentals of integration. Journal of Consciousness Studies, 14(4), 4-49.

Morgan, W.D., Morgan, S.T., \& Germer, C.K. (2016). Cultivar a atenção e a compaixão. Em C.K. Germer, R.D. Siegel \& P.R. Fulton (Orgs.). Mindfulness e psicoterapia (pp. 78-96). Porto Alegre: Artmed.

Naranjo, C. (2005). Entre meditação e psicoterapia. Petrópolis: Vozes.

Naranjo, C. (2013). La vieja y novíssima Gestalt: actitud y práctica de um experiencialismo ateórico. Santiago: Cuatro Vientos.

Nizamis, K. (2012). 'I' without 'I am': on the presence of subjectivity in early buddhism, in the light of transcendental phenomenology. Buddhist Studies Review, 29(2), 175-250.

Olendzki, A. (2016). As raízes de mindfulness. Em C.K. Germer, R.D. Siegel \& P.R. Fulton (Orgs.). Mindfulness e psicoterapia (pp. 268-289). Porto Alegre: Artmed.

Perls, F. (1979). Escarafunchando Fritz: dentro e fora da lata de lixo. São Paulo: Summus.

Perls, F. (1977). Gestalt-terapia explicada. São Paulo: Summus.

Polster, E., \& Polster, M. (2001). Gestalt-terapia integrada. São Paulo: Summus.

Prudente, B. (2014). História da meditação: das tradições do antigo Oriente à ciência do século XXI. Scientiarum História VII. Disponível em: <http://www.hcte.ufrj.br/downloads/sh/sh7/ SH/trabalhos\%20orais\%20completos/HISTORIA-DA-MEDITACAO-DAS-TRADICOES-DO-ANTIGO-ORIENTE-A-CIENCIA-DO-SECULO-XXI.pdf>. Acesso em: 05 ago. 2019.
Resnick, R.W. (2016, September 15). An introduction to Gestalt Therapy - a contemporary dialogic/process approach [online]. Disponível em: <https:/vimeo.com/ondemand/gestaltfil$\mathrm{ms} / 181868433$ ?autoplay=1>. Acesso em: 20 maio de 2017.

Resnick, S. (1977). Gestalt-terapia com prática meditativa. Em J.O. Stevens (Ed.). Isto é Gestalt (pp. 295-302). São Paulo: Summus.

Ribeiro, J. P. (2006). Vade-mécum de Gestalt-terapia. São Paulo: Summus.

Ribeiro, M. (2019). What is compassion meditation? Disponível em: <https://positivepsychology. com/compassion-meditation/ $>$. Acesso em: 05 ago. 2019.

Roshi, C. (2018). Como dar vida às nossas vidas. Disponível em: <http://www.monjacoen.com.br/ textos-budistas/textos-da-monja-coen/142como-dar-vida-as-nossas-vidas $>$. Acesso em: 23 maio 2018.

Rosmaninho, M. T. (2010). Tornar-se terapeuta: a prática da meditação na formação do psicólogo clínico de orientação fenomenológica (Dissertação em Psicologia Clínica). Pontifícia Universidade Católica de São Paulo, São Paulo.

Rusilo, L. (2017, 17 jan.) Budismo não é religião [online]. Disponível em <https://www.youtube. com/watch?v=MdLT9-CNxts $>$. Acesso em 28 jul. 2019.

Scott, D., \& Doubleday. (2000). T. O livro de ouro do Zen: a sabedoria milenar e sua prática. Rio de Janeiro: Ediouro.

Shostrom, E. L. (1965). Three approaches to psychotherapy [film]. Santa Ana, CA: Psychological Films.

Stevens, J. O. (1988). Tornar-se presente. São Paulo: Summus.

Stoehr, T. (1994) Here now next: Paul Goodman and the origins of Gestalt therapy. New York: Routledge.

Sugawara, K. (sem data). Shikantaza (apenas sentar). International Department of Soto Zen Buddhism Administrative Headquarters. Disponível em: $<$ https://global.sotozen-net.or.jp/por/library/ key_terms/pdf/key_terms01.pdf $>$.

Surrey, J.L., \& Kramer, G. (2016). Mindfulness relacional. Em C.K. Germer, R.D. Siegel \& P.R. Fulton (Orgs.). Mindfulness e psicoterapia (pp. 97114). Porto Alegre: Artmed. 
Suzuki, D.T. (1956). Zen Buddhism: selected writings of D.T. Suzuki. Garden City, NY: Doubleday Anchor Books.

Suzuki, D.T. (2017). Uma introdução ao zen-budismo. São Paulo: Mantra.

Suzuki, S. (1994). Mente zen, mente de principiante. São Paulo: Palas Athena.

Távora, C.B. (2014). Self e suas funções. Em L.M. Frazão \& K.O. Fukimitsu (Orgs.). Gestalt-terapia: conceitos fundamentais (pp. 63-87). São Paulo: Summus.

Tsallis, A.C. (2014). Indiferença criativa: uma possibilidade pragmática do método fenomenológico. Em L.M. Frazão \& K.O. Fukimitsu (Orgs.). Gestalt-terapia: conceitos fundamentais (pp. 163-179). São Paulo: Summus.

Van Dusen, W. (1977). Wu-wei, não-mente e o vazio fértil. Em J.O. Stevens (Org.). Isto é Gestalt (pp. 123-132). São Paulo: Summus.

Veras, R.P. (2013). A influência do pensamento oriental na Gestalt-terapia. Em L.M. Frazão \& K.O. Fukimitsu (Orgs.). Gestalt-terapia: fundamentos epistemológicos e influências filosóficas (pp. 157-177). São Paulo: Summus.

Veras, R.P. (2005). Ilumina-ação: diálogos entre Gestalt-terapia e Zen-Budismo (Dissertação em Psicologia Clínica). Pontifícia Universidade Católica de São Paulo, São Paulo.
Walsh, R. \& Shapiro, S.L. (2006). The Meeting of Meditative Disciplines and Western Psychology: a mutually enriching dialogue. American Psychologist, 61(3), 227-239.

Watts, A. (2003). Become what you are. Boulder, CO: Shambala.

Watts, A. (2016). O espírito do Zen: um caminho para a vida, o trabalho e a arte no Extremo Oriente. Porto Alegre: L\&PM.

Yontef, G.M. \& Jacobs, L. (2010). Gestalt Therapy. Em R.J. Corsini \& D. Wedding, D. (Eds.). Current psychotherapies (pp. 342-382). Belmont, CA: Cengage.

Zinker, J. (1977). Creative process in Gestalt therapy. New York: Vintage Books.

Fábio Nogueira Pereira (Orcid 0000-0002-65363350), Faculdades Integradas São Pedro. Endereço Institucional: Av. Vitória, 2220 - Monte Belo, Vitória - ES, 29053-360. Email: fabio.nogueira@faesa.br

Recebido em 17/10/2019

Decisão editorial em 17/06/2020

Aceito em 07/07/2020 